\title{
Analysis of the Outlooks on Life of Medical Students in the Border Ethnic Areas
}

\author{
Genliang Li ${ }^{\mathrm{a}}$, Cenhan Huang ${ }^{\mathrm{b}^{*}}$ \\ Basic Medical College, Youjiang Medical University for Nationalities, Baise, Guangxi 533000, The \\ People's Republic of China \\ aemail: ligenliang@163.com, bemail: h1975@qq.com \\ * The corresponding author
}

Keywords: Border area; Ethnic minority; Medical students; Outlook on life

\begin{abstract}
The research analyzed the current situations of their outlook on life of college students and its influence factors, as well as their realistic pressures, on the basis of questionnaire survey. 955 post-90s students of Youjiang Medical University for Nationalities, ethnic medical university in guangxi, in the border areas of China, were used as statistic object in the study. Overall, those students' outlook on life is positive, especially on self-improvement and selfless dedication to society. It is obviously influced by gender and educational background, as well as family and friends, life experience and school education. The realistic pressures mainly are from learning and employment. Therefore, during the cultivation of the students' outlooks on life, we should bring the educational function of family, friends and school into full play to them, simultaneously pay more attention to the variable factors in the student's growing environment to alleviate their pressures to learn and carry out psychological conducting on employment to reduce their employment pressures.
\end{abstract}

\section{Introduction}

The formation of correct outlook on life is not only indispensible to the healthy development of individuals, but also has a profound significance in cultivating and practicing social core values and the development of the whole society[1-4]. Medical students in the border ethnic areas are the main reserve forces for constructing elite health care team and great assets of construction and development of medical treatment causes in the border ethnic areas. Through the present study, we can grasp the status-quo of the outlooks on life of these post-90's medical students who have been deeply influenced by multi-culture and "the growing pain" for a long time under the new environment and possible problems can be analyzed[4]. The result will provide reference for making educational programs and guide students to form correct outlooks on life, thus contributing to the effective cultivation and practice of social core values and the cultivation of more qualified medical staff for the border ethnic areas. Therefore, the study is of significance both in theory and practice.

\section{Objects and methods}

Research objects. Undergraduates majoring in clinical medicine, nursing, pharmacy and the three-year students majoring in pharmacy of each grade in Youjiang Medical University for Nationalities were tested. A total of 1201 questionnaires were issued. 1135 of them were returned with a response rate of $94.5 \%$ and 955 of them were retrieved with an effective rate of $84.1 \%$.

Questionnaires. The research adopted the life cognitive scale which was compiled by Shi and Li, Zang and Liu to study the university students' outlooks on life[5,6]. The life cognitive scale consisted of 3 fractal dimensions on life goals and 2 fractal dimensions on life-styles. The former represented the pursuit of utility and 
practicality (PUP), of self-improvement and self-development (SISD), and of services for the society and collectivity (SSC). The latter represented the way of struggle (WS) and the way of relaxation (WR). The PUP was the pursuit of personal life satisfaction while the SISD was the pursuit of personal spirit satisfaction. The SSC emphasized selfless contribution to the nation, society and collectivity, while The WS and the WR respectively emphasized the realization of life goals in a way of tense struggle and leisure relaxation. The scale had good reliability and validity. The coefficient of split-half reliability (Guttman Split-Half) was 0.82, and that of validity (KMO and Bartlett test) was 0.83 . The five point scoring method ( 1 for Min, 5 for Max) was used to score the questionnaire.

Investigation methods. The investigators arranged the time, venue, and explained the necessary specifications to subjects according to the instructions of the questionnaire. The test time was about 25 minutes. The examiners took back all the questionnaires when the test was over, and the data was collected in June, 2014.

Statistical process. All the statistics was processed by SPSS19.0. Analysis of variance were used to compare the significances of influence of gender and different education background (undergraduate or specialist) on college students' outlooks on life. The significance level of statistics analysis was set as 0.05 . The mean comparison chart of each factor was drawn with software like Origin 8.0.

\section{Results}

The overall situation of the college students' outlooks on Life. In terms of the overall level, the average scores of the five dimensions of the cognitive life scale for college students were all more than the middle value of 3 points $(n=955)$. The specific scores from high to low were as follows: SISD, SSC, WS, WR and PUP. The results of two-factor multivariate analysis of variance showed that different factors had different influences on college students' outlooks on life (Tab. 1 and Fig. 1).

Table 1 Comparison of the outlooks on life of college students $(\bar{X} \pm s$, hereinafter the same)

\begin{tabular}{|c|c|c|c|c|c|c|}
\hline & Outlooks on life & PUP & SISD & SSC & WS & WR \\
\hline \multirow{2}{*}{ Gender $(n)$} & Male(241) & $3.53 \pm 0.48$ & $4.02 \pm 0.53$ & $3.98 \pm 0.61$ & $3.65 \pm 0.51$ & $3.51 \pm 0.59$ \\
\hline & Female(714) & $3.33 \pm 0.46$ & $4.01 \pm 0.40$ & $3.96 \pm 0.59$ & $3.54 \pm 0.67$ & $3.56 \pm 0.44$ \\
\hline \multirow{3}{*}{$\begin{array}{c}\text { Educational } \\
\text { background } \\
\text { (n) }\end{array}$} & & $4.81^{* *}$ & 0.09 & 0.40 & $2.40^{*}$ & 1.16 \\
\hline & $\begin{array}{c}\text { Specialist } \\
\text { students(228) }\end{array}$ & $3.36 \pm 0.40$ & $4.07 \pm 0.42$ & $3.99 \pm 0.39$ & $3.52 \pm 0.46$ & $3.39 \pm 0.51$ \\
\hline & $\begin{array}{c}\text { Undergraduates } \\
\text { (727) }\end{array}$ & $3.39 \pm 0.51$ & $3.95 \pm 0.64$ & $3.90 \pm 0.44$ & $3.53 \pm 0.49$ & $3.54 \pm 0.56$ \\
\hline \multirow{2}{*}{\multicolumn{2}{|c|}{$\begin{array}{c}t_{\mathrm{EB}} \\
\text { Totle(955) }\end{array}$}} & 0.91 & $3.31^{* *}$ & $2.58^{* *}$ & 0.20 & $3.30^{* *}$ \\
\hline & & $3.34 \pm 0.52$ & $3.97 \pm 0.43$ & $3.92 \pm 0.43$ & $3.53 \pm 0.48$ & $3.50 \pm 0.55$ \\
\hline
\end{tabular}

Notes: ${ }^{*}$ Signific ant difference $(p<0.05) ;{ }^{* *}$ Extremely significant difference $(p<0.01)$; EB, educational background; LS, length of schooling; CT, classroom teaching.

Outlooks on life of college students of different gender and educational background. The average scores on five fractal dimensions of college students (including different gender and educational background) are showed in Table 1. The variance analysis indicated that boys and girls had statistical differences in utility ( $p$ $<0.01)$ and struggle $(p<0.05)$. The undergraduates and specialist students had extremely significant differences in the following three fractal dimensions--SISD, SSC and WR.

Life goal, life means and life evaluation of college students. The students' life goal was mainly focused on health $(16.63 \%)$, family harmony $(15.76 \%)$ and career success $(11.54 \%)$, the first three options of their main life means was struggle and enterprising (17.84\%), honest and trustworthy (16.81\%), and acting according to own ability (7.81\%), and their preference to life evaluation was optimistic and confident(18.67\%), being in a calm mood (15.84\%), and open and frank (13.16\%) (Fig. 1). 

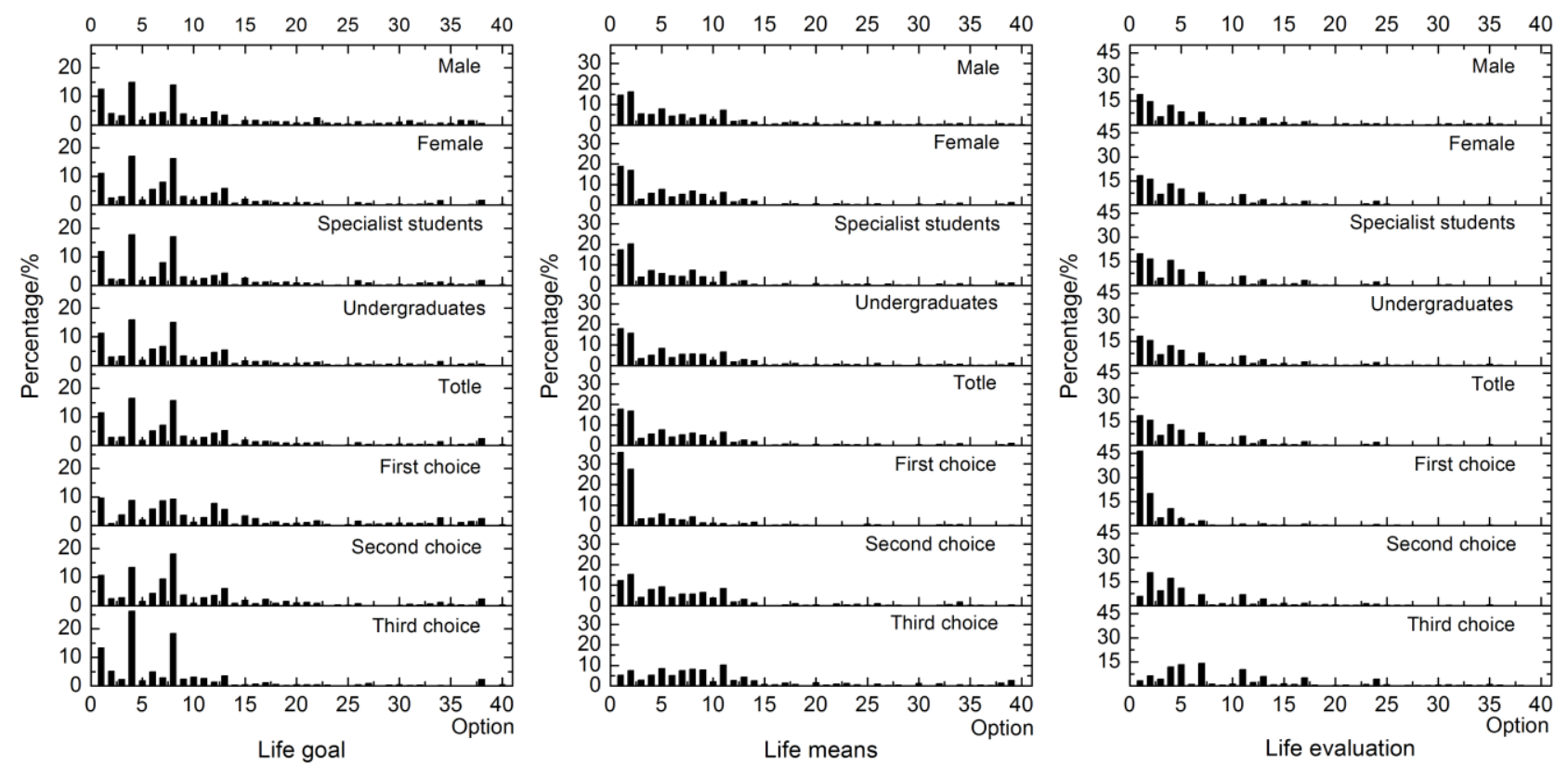

Fig. 1 Life goal, life means and life evaluation of college students.

Notes: Options of life goal: 1, career success; 2, national prosperity; 3, pure and sincere love; 4, health; 5, profound knowledge; 6 , ease of mind; 7 , sincere friendship; 8 , family harmony; 9 , happy marriage; 10 , world peace; 11 , social stability; 12 , colorful life; 13 , maintain independence; 14 , social recognition; 15 , comfort and ease; 16, dedication to society; 17, noble character; 18, enrichment; 19, smart and capable; 20, people happiness; 21, common affluence; 22, democracy and freedom; 23, idle away in seeking pleasure; 24, Soul Salvation; 25, the world admires; 26, equality and mutual benefit; 27, power and influence; 28, prominent position; 29, stability and peace; 30, establishment of reputation as an authority; 31, immortal; 32, family glory; 33, invention; 34, serve the people; 35, good-looking; 36, for the benefit of future generations; 37 , longevity; 38 , going to heaven; 39, getting superhuman ability to become immortal; 40, the next reincarnation. Options of life means: 1 , struggle and enterprising; 2 , honest and trustworthy; 3 , forethought; 4 , daring to compete; 5 , acting according to own ability; 6 , perseverance; 7 , self control; 8 , abstinence; 9 , resourcefulness adjusting to changing circumstances; 10 , work with quiet hard application; 11, mutually beneficial cooperation; 12, daring to take a risk; 13 , being conscientious to do the best; 14 , standing aloof from the worldly affairs; 15 , doing only according to his will.; 16, humiliation; 17, unconventional; 18, woolly headed; 19, unscrupulous; 20, to stop working for a little success; 21, resigning oneself to one's fate; 22, satisfied with the status quo; 23, timid; 24, sleek sophistication; 25, waiting and accepting; 26, the doctrine of the mean blending; 27, opportunistic; 28 , philander; 29, willing to quietly dedication to others; 30 , muddle along; 31 , avoidance and compromise; 32 , too observant of conventional standards; 33, injustice perfection; 34, sometimes indifferent and sometimes warm; 35, not to know what course to take; 36, free rider; 37, negative coping; 38, humble and obedient; 39, hesitation; 40, cringing. Options of life evaluation: 1, optimistic and confident; 2 , being in a calm mood; 3 , as a pleasurable occupation; 4, open and frank, 5, feeling good; 6, emptiness of boredom; 7, comfortable; 8 , anxiety and depression; 9, Worried; 10, lonely and helpless; 11 , pleasure and ease; 12 , irritability; 13 , peace of mind; 14, unreal ethereal; 15 , leisurely; 16, ablity to achieve success one way or another. 17, Self satisfaction; 18, indulge in self-admiration; 19, dispirited; 20, feelng ashamed of one's ungainly appearance; 21 , pretentious; 22, being pessimistic and worldweary; 23, excited; 24, unsuspectingly; 25, indifferent; 26, compassion; 27 , improperly belittle oneself; 28, no spirit and the doldrums; 29, being contrite and reform oneself; 30, numb and unfeeling; 31, indulge in self-delusion; 32, complainment; 33, to live as dead; 34, being backward and have no 
urge to make progress; 35, a feeling of exaltation upon fulfillment; 36, cornered; 37, arrogant; 38, complacent; 39, cocky; 40, arrogance.

Influence factors and realistic pressures of college students. The first, second and third option of the students ${ }^{6}$ influence factors were family and friends(27.31\%), life experience $(19.65 \%)$ and school education(14.03\%) (Fig. 2). Their most important realistic pressures were from both learning(31.63\%) and employment (28.73\%) (Fig. 2).
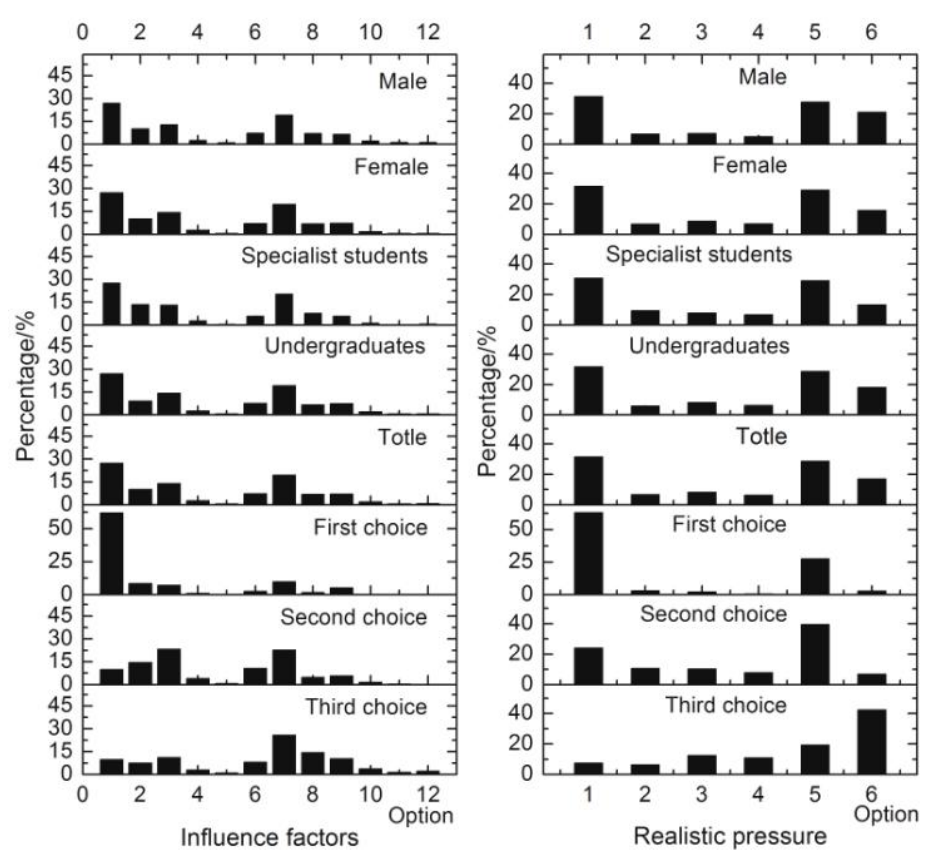

Fig. 2 Influence factors of outlooks on life and realistic pressures of college students.

Notes: Options of influence factors: 1, friends and family; 2, social change; 3, school education; 4, life accident; 5, newspapers and magazines; 6 , teachers and classmates; 7 , life experience; 8 , current life; 9 , family background; 10, outstanding person; 11, network media; 12 , other factors. Options of reaalistic presure: 1 , learning; 2, tension with parents; 3 , the tense relationship with chassmates; 4 , difficulty to communicate with teachers; 5 , employment pressure; 6 , emotional stress.

\section{Discussion}

The overall trend of college students' outlooks on life. Our investigation result showed that the college students we investigated had greater spirit of selfless dedication to the society, and they were more capable to deal with the relationship of self improvement and social development. It was similar to the results of previous investigation about the non-ethnic college students' outlooks on life ${ }^{[6,7]}$. According to the result of our investigation, the outlooks on life of college students from ethnic medical colleges and universities were energetic overall. They especially pursued self-improvement and contribution to the society and kept good balanced relationship between them. Their average scores of these two fractal dimensions were higher than those of the other three. In the aspect of life goals, they knew fairly well that life is not individual life but social life, and individual self-improvement was essential for the realization of life values. However, they were also in pursuit of utility, but had the lowest score in this dimension, which meant that they can also deal with the relationship between reality and ideality very well. In the aspect of lifestyle, they stressed struggle and relaxation as well; they can work under pressure and enjoy leisure as well.

The outlooks on life of different types of college students. As was showed in the investigation results, college students who were different in both gender and educational background had different outlooks on life. 
From the point of view of gender, boys and girls both extremely attach importance to pursuing selfimprovement and dedication to society, with no difference in these dimensions. But in pursuit of utility and struggle, there are gender differences. Boys show more utility as well as fighting spirit. Such difference from girls may be related to their different role definitions in society ${ }^{[8]}$. The differences were manifested in fractal dimensions of outlook on life as well as in their degree of identity. For instance, in the aspects of struggle and utility, there was no significant difference between undergraduates and specialist students, while significant differences were found in other aspects. Specialist students paid more attention to the pursuit of individual improvement and contribution to the society, while the undergraduates put more emphasis on relaxation and decompression.

Effect of influence factors and realistic pressures on the students' outlooks on life and relevant implications. Compared with varial influence factors and realistic pressures on the students' outlooks on life, family and friends, life experience and school education have more powerful effect on guiding and correcting the outlooks on life of college students, while both learning and employment are the main sources of student pressure. Therefore, during the cultivation and education of the students' outlooks on life, we should bring the educational function of family and school into full play to them and guide them to be good at making helpful friends, to be willing to make friends with respect and not to make bad friends, simultaneously pay more attention to the variable factors in the student's growing environment, and try to create a relaxed and lively learning environment to alleviate their pressures to learn ${ }^{[9,10]}$. With the development of society and the progress of human, the pressure of College Students' employment is increasing. Therefore we should also carry out employment guidance and employment training and psychological conducting on employment of college students, reducing students' employment pressure. It remains to be further studied.

\section{Acknowledgements}

This study was funded by the Higher Education Teaching Reform Project of Guangxi Zhuang Autonomous Region, China (2013JGA203) and Innovation Project of Guangxi Zhuang Graduate Education (JGY2015136).

\section{References}

[1] N. Perkinson-Gloor, S. Lemola, A. Grob, Sleep duration, positive attitude toward life, and academic achievement: the role of daytime tiredness, behavioral persistence, and school start times, J Adolesc 36(2013) 311-318.

[2] M. Nebhinani, N. Nebhinani, L. Tamphasana, A.D. Gaikwad, Nursing students' attitude towards suicide attempters: a study from rural part of Northern India, J Neurosci Rural Pract. 4(2013): 400-407.

[3] M. Jackson, The pursuit of happiness: the social and scientific origins of Hans Selye's natural philosophy of life, Hist Human Sci. 25(2012) 13-29.

[4] G.L. Li, S. Nong, Analysis of socialist core values on individual level of medical students in the border ethnic areas, J. Youjiang Med. Col. National. 37(2015) 126-128, 134.

[5] L. Shi, Q. Li, The psychological study of Outlook on Life, Psycholog. Sci., 21(1998): 463-464.

[6] J.F. Zhang, A study on the characteristics of the college students' life values in China, Psychological Dev. Edu. 14(1998) 26-30, 44.

[7] B.X. Yao, Y.Q He, A research on college students' outlook on life, Psycholog. Sci., 31(2008) 92, 97-99. 
[8] Y.H. Fu, F. Chen, New progress in family context influencing children's gender role socialization, J. Shanghai Norm. Univ.: Ele. Edu. Edi. 35(2006) 10-13.

[9] Y. Zhu, K. Dalal, Childhood exposure to domestic violence and attitude towards wife beating in adult life: a study of men in India, J Biosoc Sci. 42(2010) 255-269.

[10] M. Loughry, C. Eyber, Program on forced migration and health at the mailman school of public health, columbia universit, psychosocial concepts in humanitarian work with children: a review of the concepts and related literature, National Academies Press, Washington DC, 2003.

[11] H.J. Jeon, J.H. Park, E.J. Shim, Permissive attitude toward suicide and future intent in individuals with and without depression: results from a nationwide survey in Korea, J Nerv Ment Dis. 201(2013) 286-291. 